\title{
SONETO XVIII, HAMLET Y EL REY LEAR: LOS SHAKESPEARE DE NICANOR PARRA
}

\section{Efrain Kristal}

\author{
UCLA
}

\begin{abstract}
Parra ha tenido una relación particularmente significativa con tres obras de Shakespeare: el soneto XVIII, Hamlet y El rey Lear. Frente a ellas no realizó un simple trabajo de traducción, sino, más bien, una labor de apropiación, de reelaboración, mediante la cual, sin dejar de ser obras de Shakespeare, también se convirtieron en obras propias de Parra. Este ensayo explora cómo Parra trabajó esta apropiación.
\end{abstract}

Parra has had a particularly meaningful relationship with three of Shakespeare's works: sonnet XVIII, Hamlet, and King Lear. He reworked them in various ways until they became works of his own, and not just versions of Shakespeare. This article explores Parra's Shakespearian appropriations.

Efraín Kristal (Lima, 1959). Catedrático y director del departamento de literatura comparada de la Universidad de California, Los Angeles (UCLA). Ha escrito numerosos artículos y ensayos; entre ellos, Invisible Work. Borges and Translation (2002), un libro sobre el papel de la traducción en la obra de Jorge Luis Borges, e "Yves Bonnefoy and Shakespeare as a French Poet", en The Oxford Handbook to Shakespeare's Poetry, editado por Jonathan Post (2013), un ensayo sobre las traducciones de Shakespeare de Yves Bonnefoy. Hoy prepara un ensayo sobre la obra de Peter Sloterdijk. Email: kristal@ucla.edu 
or lo menos tres obras de Shakespeare han sido particularmente
significativas para Nicanor Parra: el soneto XVIII, Hamlet y El rey Lear. Parra ha trabajado con cada una de ellas con tino, como materia prima para su propio trabajo de creación. Catherine Boyle afirma que, en su traducción de El rey Lear, la pieza teatral "ha sido transfigurada por Parra en un antipoema chileno", ${ }^{1}$ y algo equivalente se podría decir de su apropiación del soneto XVIII en uno de sus poemas, y de su versión de "Ser o no ser", el monólogo de Hamlet. Parra rehace estas tres obras y las firma con nombre propio, dejando rastros de Shakespeare y de su propia actividad artística en cada una de ellas. Son ejercicios literarios que contribuyen al gran proyecto literario de Parra, a su tentativa de rescatar la poesía de un tipo de actividad literaria o intelectual que se ha alejado del mundo humano, material y natural, sucumbiendo a la retórica vacía o a la esterilidad. Uno de los temas centrales de la poesía de Parra, que se expresa a veces con humor, ironía e incluso irreverencia, es la denuncia de la poesía que se ha separado de la vida, aun cuando no encuentra cómo justificar la poesía con la generosa confianza de su hermana, una realidad que él mismo da a entender en su poema "Defensa de Violeta Parra":

Eres un manantial inagotable

De vida humana $[\ldots]$

Pero yo no confío en las palabras. ${ }^{2}$

Para afirmar la vida a su modo — complementando el modo más a flor de piel de las canciones de Violeta Parra-, la actividad literaria de Nicanor Parra se ha nutrido siempre de reflexiones sobre el papel del artista, y de una tensión entre la afirmación y el rechazo de la actividad literaria, tal como el juego de asonancias y resonancias entre los términos del título de su libro más famoso: Poemas y antipoemas.

${ }^{1}$ Catherine Boyle, "La transcripción del King Lear de Nicanor Parra: la transfiguración de la composición literaria”, en Taller de Letras 48 (2011): 159.

${ }^{2}$ Nicanor Parra, "Defensa de Violeta Parra", de Otros poemas (1950-1968), en Obras completas \& algo + / Vol. I (Barcelona: Galaxia Gutenberg - Círculo de Lectores, 2006), 228-230. A partir de ahora nos referiremos al primer volumen de las obras completas con la abreviación: $O C I$. 


\section{EL SONETO XVIII}

El desdén de Parra con la poesía que ha perdido su vigor sin duda ha inspirado su apropiación de "Shall I compare thee to a Summer's day?" (¿Te debo comparar a un día de verano?), el soneto XVIII de Shakespeare que integra como poema la colección News from Nowhere (1975). Llamado "Found Poem" (poema encontrado) ${ }^{3}$, el título del poema de Parra alude a los gestos de Marcel Duchamp mediante los cuales el artista convierte en obra de arte a algún "objeto encontrado" que antes carecía de valor artístico. El "objeto encontrado" en el "poema encontrado" de Parra es el soneto XVIII de Shakespeare, reproducido al interior del poema.

Con este mecanismo, Parra confiere un nuevo valor artístico a un poema que quizás lo ha perdido por haber sido consagrado, como aquellos clásicos que se olvidan, que apenas se leen, o que se leen por obligación o con desgano. Este nuevo valor adquiere varios sentidos: subraya el mecanismo de consagración que ha contribuido a que la obra perdiera su vitalidad para muchos de sus lectores, y ofrece indicios para reconsiderarla en términos propios, pero también como un poema del propio Parra. No hace falta saber inglés para comprobar el trabajo editorial que presupone la creación de un poema con varias tipografías, con un título que no puede ser de Shakespeare, con una nota al pie de página que incluye una referencia a una antología editada por otro editor, con un subtítulo que corresponde a una antología contemporánea y con otro subtítulo que corresponde al soneto en las ediciones que se editaron en vida de Shakespeare.

En el "Poema encontrado" Parra no cita el nombre consagratorio de Shakespeare que podría ser un impedimento para leer al soneto con ojos frescos, y lo presenta como un descubrimiento en una nota al pie de página que dice: "Descubierto en The Oxford Book of English Verse". ${ }^{4}$ La nota hace hincapié en el mecanismo de consagración del

${ }^{3}$ Nicanor Parra, "Found Poem", de News from Nowhere, en Obras completas \& algo + / Vol. II (Barcelona: Galaxia Gutenberg - Círculo de Lectores, 2011), 921. A partir de ahora nos referiremos al segundo volumen de las obras completas con la abreviación: OC II. Asimismo nos referiremos al "Found Poem" de Parra con nuestra traducción de "Poema encontrado".

${ }^{4}$ Este libro, editado por Arthur Quiller-Couch, es probablemente la antología más importante en la historia de la poesía inglesa. Fue publicada por primera vez en 1900 . 
poema por su inclusión en una antología prestigiosa. Parra no copia el soneto de Shakespeare con la tipografía de los otros poemas de su colección, sino que lo fotocopia tal como aparece en la antología. El "Poema encontrado" de Parra incluye el número 155 que corresponde a la numeración de los poemas de la antología, pero que es arbitrario no solamente para los lectores que desconocen la antología, sino incluso para quienes la conocen, porque la nota de Parra no ofrece una fecha en su referencia bibliográfica, y ese mismo soneto de Shakespeare lleva el número 145 a partir de las ediciones de 1939 de la antología y de las que se encuentran hoy por internet. La clarificación filológica de estos accidentes de la numeración del poema sería sin duda irrelevante para Parra, cuyo propósito era simplemente evocar las convenciones de una antología que ha consagrado a un poema de un autor consagrado.

En el "Poema encontrado" Parra incluye la palabra "Sonnets" en plural y en cursivas, dando a entender que el soneto que ha fotocopiado forma parte de una serie de la cual sólo se está reproduciendo el primer poema, pero en vez de reproducir el número romano "i” en minúsculas que aparece en otras ediciones bajo la palabra "Sonnets", Parra usa el número "XVIII" (en mayúsculas y en negrillas), el que corresponde a la numeración del soneto en las ediciones que se publicaron en vida de Shakespeare, y que facilitaría la ubicación del poema en cualquier libro con todos los sonetos, ya sea en inglés o en una traducción. ${ }^{5}$ Es probable que los editores de la antología de Oxford hayan usado la convención de números romanos en minúsculas para diferenciar la numeración interna de la antología de la clasificación con números romanos en mayúsculas con la que se designa a los sonetos de Shakespeare por todos sus conocedores, y que el "editor" en el poema de Parra prefiera la numeración de las ediciones de los sonetos completos al de la antología donde lo "descubrió".

Cualquier lector del poema de Parra, entonces, aun si ignora el inglés, puede advertir que el poema "encontrado" ha pasado por varios procesos editoriales en épocas distintas que un estudioso de la literatura

${ }^{5}$ En todas las ediciones de la antología que he consultado, anteriores y posteriores a 1939, el soneto que Parra reproduce no lleva el número XVIII, sino que el número "i” (a veces entre paréntesis: "[i]"), puesto que se trata del primero de los veinte sonetos de Shakespeare que aparecen en todas las ediciones de la antología. Aun si hubiera reediciones de la antología que se refieran al soneto con el número romano XVIII, se trataría de una anomalía. 
podría precisar con fechas exactas: en 1609, cuando en vida de Shakespeare aparece la primera edición de sus sonetos; en 1900, cuando se publica la antología de Oxford por primera vez, y en 1975, cuando aparece el libro de Parra con su apropiación del soneto. La voz editorial del "Poema encontrado" de Parra se presenta como un lector sensible que ha "descubierto" un valioso poema que ha sido sepultado de alguna manera en la misma antología que lo consagró. La apropiación de este poema por Parra es, claro, un gesto irónico y humorístico porque aquello que se pretende haber descubierto es uno de los sonetos más conocidos de Shakespeare en la antología más importante en la historia de la lírica inglesa.

El lector que conoce el inglés -o el que se tome la molestia de buscar una traducción feliz del soneto- puede reconocer que Parra ha elegido un poema de Shakespeare que podría releerse como si fuera un poema del propio Parra por sus vínculos temáticos con otros de sus poemas, porque uno de los temas centrales del soneto es el de la consagración de la poesía. El soneto XVIII es uno de los poemas de amor más conocidos de la literatura inglesa, en el cual la voz poética de Shakespeare compara a su amada con el efímero paso del tiempo para luego consagrarla a ella y, con ella, a la poesía que la sobrevivirá. En él Shakespeare celebra el poder de la poesía para darle vida a lo que ha muerto, al crear un contraste entre la mortalidad de la amada y la prolongación de su vida en un poema, como lo resume en su copla final:

So long as men can breathe, or eyes can see,

So long lives this, and this gives life to thee.

(Mientras los hombres respiren y ojos vean, Así vivirá este poema dándote vida. ${ }^{6}$

En un libro de poemas de Parra no es posible leer este soneto como un mero poema de amor ni como una inocente celebración de la vitali-

${ }^{6}$ La traducción del segmento es mía (E.K.). Más adelante, en el análisis de El rey Lear y de Romeo y Julieta, veremos ejemplos más complejos del recurso poético de Shakespeare mediante el cual la misma palabra adquiere múltiples significados. En este caso, "vida" significa la vida de la amada en vida, y el poder de la poesía para evocar su belleza, aun después de su muerte. 
dad de la poesía. En un libro de Parra el poema es más irónico y grave de lo que podría parecer en una antología de obras consagradas.

El tema del poder de la poesía para sobrevivir las experiencias humanas que la inspiran está presente en la poesía de Parra, pero en ella no se trata de una celebración, sino de una reflexión más sobria, como en los versos con los que concluye el último poema de Poemas y antipoemas, que lleva el título shakesperiano de "Soliloquio del individuo". Este poema reconoce el poder de la poesía para constatar lo pasajero de la experiencia humana, pero no pretende que la poesía prolongue la vida misma más allá de la muerte. El "Soliloquio" concluye cuando el hombre moderno afirma, para luego negar, nostalgias por sus orígenes antiquísimos y por el origen del arte y la poesía que dejan vestigios de la experiencia vivida:

Mejor es tal vez que vuelva a ese valle,

A esa roca que me sirvió de hogar,

Y empiece a grabar de nuevo,

De atrás para adelante grabar

El mundo al revés.

Pero no: la vida no tiene sentido. ${ }^{7}$

El "Soliloquio del Individuo", como el soneto XVIII de Shakespeare y el "Poema encontrado" afirman, de una u otra manera, la sobrevivencia de la experiencia humana en la poesía; pero los poemas de Parra añaden una nota de desgarramiento a esta idea poética cuando hacen hincapié en que este tipo de sobrevivencia presupone el sinsentido de la vida y la finalidad de la muerte. Así, el tema de la consagración de la poesía en el soneto de Shakespeare copiado en un poema de Parra adquiere un nuevo significado, y se transforma en un poema de Parra. A la luz de su poesía, la conclusión del soneto XVIII no puede leerse como una afirmación de la poesía - como si ésta fuera una compensación suficiente por lo pasajero que puede ser la experiencia humana-, sino como una constatación de que la consagración de esta idea poética puede ser una coartada para no tener que enfrentarse a la miseria o al sinsentido de la vida. El "Poema encontrado" de Parra es, entonces, un

${ }^{7}$ Nicanor Parra, "Soliloquio del Individuo", de Poemas y antipoemas, en OC $I, 64$. 
antipoema, y es también un poema "descubierto" en una antología en la cual sus lectores lo han leído frecuentemente como un poema que celebra el amor y el poder consagratorio de la poesía, lectores que - para Parra - no lo han leído ni comprendido precisamente porque se trata de un clásico.

\section{"SER O NO SER"}

El título del "Soliloquio del Individuo" tiene connotaciones shakesperianas porque, al igual que "Ser o no ser", el monólogo más famoso del teatro inglés, se trata de una interrogación sobre la existencia humana en la cual la voz poética no sabe cómo darle un sentido a la vida. La relación entre este tema de Parra y el monólogo de Shakespeare no es arbitraria ni accidental: en Hojas de Parra (1985) aparece una versión del monólogo de Shakespeare bajo el título "Ser o no ser". 8 Tal como en su apropiación del soneto XVIII, Parra no cita el nombre de Shakespeare en el poema, tampoco el nombre del personaje Hamlet ni el título de la obra Hamlet, y no indica que se trata de una versión literaria. Eso dicho, Parra tiene toda la razón en firmar el poema como un poema original, porque al trabajar con el original de Shakespeare se toma la libertad de recortar, añadir y modificar el texto hasta transformarlo en su propia creación.

Al igual que el "Poema encontrado", el "Ser o no ser" de Hojas de Parra es un poema del autor de Poemas y antipoemas. Su tema evoca un asunto que no está en el original de Shakespeare, pero que corresponde a las preocupaciones literarias de Parra, y cabe aquí evocar nuevamente al "Soliloquio del Individuo", que se puede leer como un monólogo teatral por su título y porque se trata de una meditación sobre la razón de ser de la vida expresada con una voz poética a la vez individual y colectiva, digna de Walt Whitman. El "soliloquio" de Parra usa la anáfora "Yo soy el Individuo" para anunciar las etapas de la evolución humana desde la prehistoria hasta el presente. El "Individuo" de Parra pasa de la edad de piedra, al neolítico, a la revolución industrial para llegar a un presente indeseable. El poema incluye una afirmación de la consabida suspicacia de Parra hacia la actividad in-

\footnotetext{
${ }^{8}$ Nicanor Parra, "Ser o no ser", de Hojas de Parra, en OC II, 246.
} 
telectual que se aleja de la vida: "Bien. Me puse a pensar un poco, / Preguntas estúpidas se me venían a la cabeza, / Falsos problemas." "9 $\mathrm{Y}$ elabora también su preferencia por la fuerza creadora del mundo natural con intimaciones espirituales para expresar dudas sobre el mundo de la tecnología: "Alguien segregaba planetas,/ ¡Arboles segregaba!/ Pero yo segregaba herramientas." 10 Al final de una larga meditación sobre la evolución humana, la voz poética de Parra expresa un deseo de regresar a sus orígenes con la metáfora del "valle" como la morada del ser humano.

El "Ser o no ser" de Parra usa la misma metáfora del "valle" para ofrecer una idea poética equivalente, una meditación sobre la inmovilización del espíritu que "nos obliga a vegetar en este valle de lágrimas / en vez de emigrar a otros desconocidos". ${ }^{11}$ Para apreciar la transformación del texto de Shakespeare en un poema de Parra, vale la pena comparar este momento clave del monólogo de Hamlet con la estrofa equivalente del poema de Parra:

...who would these fardels bear,

To grunt and sweat under a weary life,

But that the dread of something after death

The undiscover' $d$ country, from whose bourn

No traveller returns- puzzles the will,

And makes us rather bear those ills we have

Than fly to others that we know not of?

por qué seguir sudando y refunfuñando

bajo la carga de una vida abyecta

sólo porque el temor a la incógnita del más allá

ignorado país de donde nunca

ningún viajero regresa jamás

inmoviliza al espíritu

y nos obliga a vegetar en este valle de lágrimas

en vez de emigrar a otros desconocidos. ${ }^{12}$

\footnotetext{
${ }^{9}$ Parra, "Soliloquio", 62.

${ }^{10}$ Ibídem, 63.

${ }^{11}$ Nicanor Parra, "Ser o no ser", 247.

12 Ídem.
} 
La imagen del "valle" forma parte del vocabulario poético de Parra $\mathrm{y}$, como puede verse, es un añadido al soliloquio de Shakespeare, que no usa esa palabra.

En el monólogo de Shakespeare, Hamlet considera la muerte como una salida a los sufrimientos de la vida, pero decide seguir viviendo cuando considera la posibilidad de que los sufrimientos del más allá podrían ser aun peores que los del aquí y el ahora. Parra elimina esta comparación entre los sufrimientos de esta vida y los posibles terrores del más allá, porque su versión del "Ser o no ser" desarrolla un argumento distinto, ajeno a la obra de Shakespeare. Parra corrige las preocupaciones de Hamlet cuando dice "por qué seguir sudando y refunfuñando / bajo la carga de una vida abyecta / sólo por el temor a la incógnita del más allá". El "sólo" de Parra lo cambia todo. Para Hamlet el temor a la incógnita del más allá es precisamente la razón por la cual no se suicida, pero en el poema de Parra, la incógnita del más allá es una traba para "vegetar en este valle de lágrimas / en vez de emigrar a otros desconocidos". Mientras que en el original, Shakespeare crea un contraste entre el conocido aquí y el desconocido más allá, Parra crea un contraste entre "este valle" de lágrimas y "otros valles desconocidos". Si Hamlet opta por la vida debido a su preocupación con las incógnitas del más allá, el poema de Parra señala que la preocupación con el más allá puede inmovilizar al espíritu humano como un obstáculo para imaginar otras posibilidades en el aquí y el ahora (tal como los falsos problemas de la filosofía y la metafísica que Parra ha criticado en tantos de sus poemas). No hay en Parra, como en el monólogo de Hamlet, una expresión de temor a la muerte ni un respeto a las enseñanzas de la iglesia, sino una frustración por la incapacidad del ser humano en el aquí y el ahora para encontrar salidas a los problemas de la humanidad. En su versión del monólogo de Hamlet, Parra compara el mundo que nos ha tocado vivir con otros mundos que el ser humano podría concebir en el aquí y el ahora, y esta visión es compatible con sus simpatías socialistas.

Esta preocupación sobre el ser humano que se siente paralizado en un mundo abyecto le da al "Ser o no ser" de Parra vínculos más próximos con su propia poesía que con la obra de Shakespeare.

Comparemos dos versos claves del "Ser o no ser" con los últimos versos de Poemas y antipoemas: 
"Ser o no ser":

El temor a la incógnita del más allá [...]

nos obliga a vegetar en este valle de lágrimas

en vez de emigrar a otros desconocidos.

"El soliloquio del Individuo":

Mejor es tal vez que vuelva a ese valle $[\ldots]$

Pero no: la vida no tiene sentido.

"El soliloquio del Individuo" y "Ser o no ser" no son excepciones a la regla, porque la poesía de Parra no exhibe ansiedades como las de Hamlet sobre el más allá ni sobre las consecuencias del suicidio. En el "Discurso fúnebre", de Versos de salón, la voz poética de Parra afirma que "el ataúd lo cura todo". ${ }^{13}$ En su "Padre nuestro" imagina a Dios como "un hombre vulgar y corriente" al que le pide "no pienses más en nosotros", y le asegura que los humanos "perdonamos todo". ${ }^{14}$ Parra transforma la ansiedad de Hamlet por sus pecados en una expresión del derecho a la insolencia en contra de las enseñanzas de la iglesia. En su "Agnus dei", la voz poética de Parra defiende su derecho a la sexualidad en contra de la moral cristiana cuando se dirige a Jesucristo:

Cordero de dios que lavas los pecados del mundo [...]

Déjanos fornicar tranquilamente:

No te inmiscuyas en ese momento sagrado. ${ }^{15}$

La irreverencia de estos versos está lejos de las preocupaciones de Hamlet sobre la sexualidad como un pecado, no solamente en sus invectivas en contra de la sexualidad de su madre, de su tío y de Ofelia, sino también cuando piensa en su propia sexualidad. Para muchos comentaristas, los "thousand natural schocks / That flesh is heir to" de Hamlet se refieren a sus ansiedades sexuales. Hay traductores al español que resaltan este aspecto, como en la traducción de Guillermo Macpherson, que subraya: "los mil tormentos, de la carne herencia"; o

\footnotetext{
${ }^{13}$ Nicanor Parra, "Discurso fúnebre", de Versos de salón, en OC I, 136.

${ }^{14}$ Nicanor Parra, "Padre nuestro", de La camisa de fuerza, en OC I, 185.

${ }^{15}$ Nicanor Parra, “Agnus Dei”, de La camisa de fuerza, en OC I, 186.
} 
la de Manuel Ángel Conejero, que dice: "todos los males, herencia de la carne". Parra, en cambio, traduce esta idea como: "los miles de riesgos naturales / a que se expone la mísera carne". ${ }^{16}$ Hay en Parra anhelos espirituales que ha expresado con un lenguaje cristiano, pero no hay en él sentimientos de culpa por lo que ha vivido y, sobre todo, no los hay por la sexualidad. En "Yo pecador", la voz poética de Parra hace una serie de confesiones sobre sus pecados. Se confiesa "delincuente nato" y pide "perdón a diestra y siniestra"; sin embargo, termina: "Pero no me declaro culpable". ${ }^{17}$

En un poema escrito en inglés, Parra ofrece una interpretación de Hamlet que corresponde a su poema, pero no a las preocupaciones del personaje en el original de Shakespeare. El poema "H according to N"18 (que es una probable abreviatura de "Hamlet según Nicanor") ofrece esta interpretación de Hamlet:

What inhibits Hamlet

Is his tragical knowledge

Of the futility \& Folly of action

In a world out of joint

Knowledge Kills action

(Aquello que cohíbe a Hamlet

Es su conocimiento trágico

De la futilidad y la locura de la acción

En un mundo dislocado

El conocimiento mata a la acción)

La interpretación de Hamlet de este breve poema coincide con su transformación del monólogo de Shakespeare, porque la voz poética de Parra hace hincapié en los impedimentos a la acción en el mundo que nos ha tocado vivir y no en sus preocupaciones metafísicas o teológicas con relación al más allá. Es así que a partir de su propio Hamlet, o de

${ }^{16}$ Las citas de las traducciones al español se pueden consultar por internet: http://4umi.com/shakespeare/hamlet/es.

${ }^{17}$ Nicanor Parra, "Yo pecador", de La camisa de fuerza, en OC I, 188.

18 Nicanor Parra, "H according to N," de Antipoems: How to Look Better \& Feel Great, en OC II, 314. 
su interpretación de Hamlet, Parra crea también un vínculo sugerente entre el personaje de Shakespeare y el protagonista de Pedro Páramo. En "Paralelo con Hamlet", ${ }^{19}$ uno de sus textos dedicados a Juan Rulfo, el poeta ofrece una meditación sobre Juan Preciado, el personaje que va en busca de su padre, quien es también el padre de muchos otros hijos abandonados. El poema de Parra establece una paralelo entre el príncipe de Dinamarca de Shakespeare y el hijo natural de Rulfo, por el tema de la venganza, pero hace hincapié en el aquí y el ahora, en el aspecto económico de las preocupaciones del personaje de Rulfo. El poema de Parra cita con letras mayúsculas las palabras de la madre abandonada de Juan Preciado, cuando, antes de su viaje, le dice "CÓBRASELO CARO HIJO MÍO”, y el poema también insiste en las reivindicaciones materiales por su condición de hijo abandonado cuando recuerda que "Juan Preciado no tiene mucho de príncipe", que es "+ mendigo que rey". El contraste entre "rey" para sugerir el poder y "mendigo" para sugerir la condición del desposeído es también una de las preocupaciones centrales de Parra en su traducción de El rey Lear.

\section{LEAR. REYY MENDIGO}

En una escala mayor, el acercamiento de Parra a El rey Lear es semejante a su trabajo con Hamlet y a su apropiación del soneto XVIII. Es evidente que Parra ha trabajado con el original de Shakespeare, pero que también ha leído otras traducciones con detenimiento; ${ }^{20}$ que ha

${ }^{19}$ Nicanor Parra, "Paralelo con Hamlet", de "Mai mai peñi (Discurso de Guadalajara)", en OC II, 577.

${ }^{20}$ Esta lectura se puede ver en cómo modificó las elecciones de otros traductores, como cuando traduce "your houseless heads and unfed sides" con una frase que parece una variante de la traducción a cargo de Manuel Ángel Conejero. Parra dice: "Cómo podrán vuestras testas sin techo/ vuestros estómagos vacíos... protegeros de un tiempo como éste"; mientras Conejero dice: "Cómo podrán defenderos vuestras testas sin techo, vuestro vientre vacío... de un tiempo así". Ver William Shakespeare, El rey Lear, edición y traducción: Instituto Shakespeare, bajo la dirección de Manuel Ángel Conejero (Madrid: Alianza Editorial, 2009), 87

Se adivina también que Parra podría haberse beneficiado de la versión de Juan Enseñat, como en este ejemplo. Parra traduce: "Soplad vientos/ Hasta hacer explotar vuestras mejillas! (Lear. Rey y mendigo, OC II, 444), cuando Enseñat había traducido: "iSoplad vientos, soplad hasta que revienten vuestras hinchadas mejillas!" (W. Shakespeare, El rey Lear, traducido por Juan B. Enseñat (Barcelona: Feliz Costa, 1913), 49. 
estudiado versiones cinematográficas de la obra, como la de Grigori Kózintsev, y es seguro también que el trabajo del director Raúl Osorio y de los actores de la producción teatral que aprovechó su primera versión de la obra en 1992 haya tenido también algún impacto en la versión publicada doce años después, en 2004.

Al igual que con la apropiación del soneto XVIII, la traducción de Parra incluye rastros y vestigios de una serie de registros literarios de diversas fuentes y tiempos. Al igual que con su versión de "Ser o no ser", Parra se toma libertades con el original. Al igual que con los dos ejercicios previos, Parra transforma la obra de Shakespeare en una obra digna de Parra, que obedece a sus propias preocupaciones literarias y que, en consecuencia, firma con nombre propio. ${ }^{21}$ Parra recrea el lenguaje de Shakespeare, pero modifica también sus contenidos. Por ello los editores de las Obras completas de Parra afirman con justicia que la obra "pertenece tanto al autor como al traductor". ${ }^{22}$

El aspecto más notable del estilo de Parra en su traducción de $E l$ rey Lear es su mezcla de registros lingüísticos y literarios. En la traducción conviven el lenguaje del teatro del Siglo de Oro (matizado sin duda por una historia chilena de la representación del teatro clásico español); un español contemporáneo neutro y directo; coloquialismos latinoamericanos ("eres un cero a la izquierda") 23; chilenismos ("Les pasaste la huasca" 24 o "Tata" en vez de "nuncle", que usualmente se traduciría como "mi tío" o "mi amo"); palabras y parlamentos en inglés e incluso en otros idiomas como el italiano o el alemán. A veces, los registros se mezclan y crean efectos cómicos, como cuando un personaje dice: "Caramba, Su majestad". ${ }^{25}$

En el Lear de Parra, un mismo personaje puede pasar de un registro lingüístico a otro, como cuando Kent, el fiel servidor de Lear, expresa su cólera con Oswald, el arrogante y mentiroso servidor de sus

${ }^{21}$ Es así como Parra explica el haber excluido el nombre de Shakespeare de la portada de su Lear. Rey y mendigo en un texto citado en las notas de las obras completas: "Al decir Lear, el lector dice Shakespeare, de manera que su nombre no es necesario. Basta con el mío, no más”, OC II, 1074.

${ }^{22}$ Notas de los editores (Niall Binns, Ignacio Echevarría y Adán Méndez), en OC II, 1073.

${ }^{23}$ Parra, Lear, OC II, 389.

${ }^{24}$ Ibídem, 388.

${ }^{25}$ Ibídem, 446. 
hijas Goneril y Regan. En una letanía de insultos, Kent usa españolismos como los que aparecen en otras traducciones españolas ("bellaco", "lacayo", etcétera.) ${ }^{26}$, latinoamericanismos ("carajo", "cabrón", etcétera.) $)^{27}$, expresiones contemporáneas ("esclavo químicamente puro", "los muros del wáter") ${ }^{28}$, e incluso algunas palabras en inglés ("Lady Vanity"). De forma análoga, puede pasar de un giro contemporáneo y coloquial ("traidor archirreconocido") ${ }^{29}$ para luego usar un vocabulario que sugiere lo arcaico ("vuestra alcurnia") ${ }^{30}$.

La traducción de Parra incluye también alusiones literarias ajenas a Shakespeare, como sus repetidas referencias a Cervantes, con las cuales Parra elogia la gran tradición literaria de su propia lengua. Así, por ejemplo, un texto en Shakespeare en el que se menciona a un caballero y su escudero se transforma en una alusión directa a Don Quijote gracias a la mención de Dulcinea que evidentemente no está en el original:

No más brujas a la hoguera

Sino perseguidores de Dulcineas

Cuando todos tengamos la razón

Ningún escudero en deuda

Ningún caballero pobre. ${ }^{31}$

A veces las alusiones literarias son contemporáneas, como a la Dolce vita de Fellini ("La dolce vita acabará como ellos") $)^{32}$, o cuando decide mantener la palabra "Howl" (aullido) en inglés cuando Lear grita: "Howl howl howl!". La traducción de la palabra "Howl" no presenta ninguna dificultad al traductor, pero se trata del título del poema más famoso de Allen Ginsberg y quizás de la poesía norteamericana en la segunda mitad del siglo veinte. El poema de Ginsberg viene al caso en la traducción de Parra, porque expresa el malestar de una generación que ha sucumbido a la desesperación y a locura. La primera imagen del poema de Ginsberg tiene un sabor de actualidad inmediata, pero es tam-

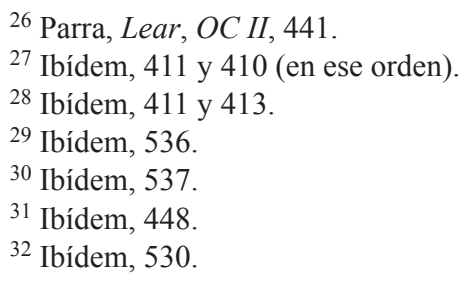


bién heredera de la escena de la tormenta, cuando, hambriento y desesperado, Lear ha sucumbido al desvarío:

I saw the best minds of my generation destroyed by madness, starving hysterical naked ${ }^{33}$

(He visto a las mejores mentes de mi generación destruidas por la locura, hambrientos histéricos desnudos)

La alusión al poema de Ginsberg en la traducción de Parra puede ser también una manera de hacer un homenaje a un poeta norteamericano amigo y cercano, porque los poetas de la generación de Ginsberg han citado a Parra como una influencia, y porque el propio Ginsberg y Lawrence Ferlinghetti tradujeron el "Soliloquio del individuo" y editaron la primera edición en inglés de Poemas y antipoemas. ${ }^{34}$ El saludo al poema de Ginsberg encaja en una obra en la que conviven registros literarios del pasado y del presente.

Es evidente que Parra tuvo dificultades con algunos de los textos más difíciles de Shakespeare, como los del bufón (a quien Parra se refiere con el nombre inglés, "Fool") y los de Edgar (el hijo de Gloucester) cuando finge que el diablo lo ha poseído. A veces Parra mantiene el inglés al lado de su traducción de estos textos difíciles, y otras veces copia un inglés que no traduce. A veces reemplaza algunos de estos parlamentos espinosos con textos de la cultura popular latinoamericana, como cuando, por ejemplo, transcribe una canción de niños a la que

${ }^{33}$ Allen Ginsberg, Howl (San Francisco: City Lights, 1956), 9. La traducción es mía (E. K.).

${ }^{34}$ Este es un recuerdo de Allen Ginsberg: "Nicanor Parra es un viejo amigo mío y de Lawrence Ferlinghetti. De hecho, Ferlinghetti publicó su primer libro en los Estados Unidos, y los dos trabajamos en la traducción de un poema de larga o mediana talla ("Soliloquio del individuo")" [traducción mía del texto original: "Nicanor Parra is an old friend of (Lawrence) Ferlinghetti and myself. In fact, Ferlinghetti published his first book in the United States, Antipoems (Pocket Poets \#12, City Lights, 1960), and we both worked on translations of one long poem, or middle-sized poem, of that time ("Soliloquio del Individuo" - "The Soliloquy of the Individual" or "The Individual Soliloquy"]. Citado en internet por el proyecto Ginsberg: http://ginsbergblog.blogspot.com/2011/09/nicanor-parra.html.

Cabe añadir que la edición de Poemas y antipoemas en inglés es una selección y lleva el título Anti-Poems, cuyo guión es un modo ingenioso de mantener la tensión entre las palabras "poemas" y "antipoemas" del título original. Entre los traductores de esa primera edición figura el nombre de Fernando Alegría. 
añade un colofón propio en vez de traducir un parlamento complejo de Shakespeare que incluye una conjura para asustar a una bruja:

Swithold footed thrice the 'old;

He met the nightmare, and her ninefold;

Bid her alight,

And her troth plight.

And aroint thee, witch, aroint thee! ${ }^{35}$

Que llueva que llueva

La vieja está en la cueva,

Los pajarillos cantan

La vieja se levanta.

Vade retro bruja vade retro. ${ }^{36}$

El lenguaje de la traducción de Parra es, entonces, una amalgama de registros diversos en la que conviven coloquialismos, chilenismos, el lenguaje del teatro clásico español, alusiones literarias de diversas épocas que Shakespeare nunca pudo haber conocido. Eso dicho, en todos sus registros (salvo cuando mantiene el inglés de Shakespeare) el lenguaje de Parra es sencillo y directo. A Parra no le interesa reproducir los efectos poéticos de Shakespeare, y prefiere la traducción directa (o la transformación para sus propios fines) de alguna idea detrás de las complejas figuras poéticas del original. Tomemos, por ejemplo, unos versos compactos en los que se despliega el complejo y poderoso lenguaje poético de Shakespeare en El rey Lear:

I know not how conceit may rob

The treasury of life when life itself

Yields to the theft. ${ }^{37}$

35 William Shakespeare, King Lear, editada por Kenneth Muir (Londres y Nueva York: The Arden Shakespeare, 1972) III, iv, 116. Todas nuestras citas en inglés de El rey Lear provienen de la edición de Kenneth Muir, pero hemos consultado otras ediciones y concordancias que no ha sido necesario citar. Para cada referencia al texto en inglés citaremos el acto, la escena y la página.

${ }^{36}$ Parra, Lear, OC II, 458.

${ }^{37}$ Shakespeare, King Lear, IV, vi, 161 (para las citas en inglés ofrecemos el acto, la escena y el número de página de la edición que estamos citando). 
El que habla en este parlamento es Edgar, que ha encontrado una coartada para salvar la vida de su padre que ha tomado la decisión de suicidarse. El poderoso efecto poético y emotivo de Shakespeare depende del dolor que siente el hijo por el sufrimiento del padre, y por su determinación de salvarle la vida y protegerlo de la humillación. A nivel de su lenguaje figurativo, estas ideas se despliegan con el uso complejo — digno de los conceptos poéticos entrecruzados que Gracián analiza en su Arte del ingenio - de una serie de metáforas, metonimias y personificaciones: la metáfora del robo para referirse a la muerte, la metáfora del tesoro para referirse al vida, la metonimia de vida para referirse al ser humano, la personificación de la vida como si se tratara de un individuo que permite un robo. Parra elimina todos los tropos poéticos de Shakespeare con una traducción más directa y con una sola metáfora - la vida como un camino-, más simple, y su traducción establece una distancia emotiva entre Edgar y su padre que no existe en el original, pero que corresponde a otros cambios que va a llevar a cabo con el contenido de la obra para criticar las prerrogativas de los nobles:

Qué capricho del hombre

Renunciar a su propia vida

Cuando la vida misma va a la muerte. ${ }^{38}$

La traducción de Parra es consistente con su visión de la obra en la que los personajes nobles, como Gloucester y el propio Lear, sufrirán humillaciones y caerán de sus pedestales en un mundo corrupto y abyecto, aun cuando se den cuenta de sus errores. En el original, Edgar muestra respeto y compasión por su padre y en ningún momento hablaría de sus acciones como "caprichos", como en la versión de Parra. En éste y otros casos, Parra está más comprometido con la creación de su propio mundo poético que con la reproducción de los efectos poéticos de Shakespeare, sobre todo cuando los conceptos poéticos de este último van a contrapelo de los cambios que Parra lleva a cabo con el contenido de la obra.

Eso dicho, a veces las destilaciones de Shakespeare producen versos poéticos de gran intensidad en el contexto del mundo poético de Parra. Si, por ejemplo, Shakespeare dice "That's something yet:

\footnotetext{
${ }^{38}$ Parra, Lear, OC II, 501.
} 
Edgar I nothing am"39, que se podría traducir como "Algo sería yo por lo menos: que Edgar ya no es nada" 40 , Parra lo transforma en un pequeño e intenso poema cuyo efecto poético depende de su presión con la gramática del idioma: "Lo que es yo no soy nada" 41 . Cuando Lear se queja de la ingratitud de una hija antes de saber que ésta le será aún más cruel, dice: "She had tied / Sharp-toothed unkindness, like a vulture, here"42 ("Ha clavado / el afilado pico de la ingratitud, como un buitre, aquí." ${ }^{43}$ ), que Parra depura con: "Ha clavado [...] / los dientes puros de la ingratitud" 44 . Otras destilaciones producen los siguientes versos, que podrían contribuir a una notable antología de micropoemas de Parra: "La necesidad tiene cara de hereje" "45; "El terror de la tierra"46; "es sólo un hombre entre los hombres" 47 ; "Esto es el hombre? Nada más que esto?"48; "huele a mortalidad"49.

\section{PARRA Y NERUDA}

El acercamiento de Parra con Shakespeare tiene algunas semejanzas y diferencias interesantes con el de Pablo Neruda en su traducción de Romeo y Julieta. Tanto Neruda como Parra proyectan sus propias preocupaciones vitales, e incluso políticas ${ }^{50}$, en sus traducciones de

${ }^{39}$ Shakespeare, King Lear, II, iii, 77.
${ }^{40}$ Shakespeare, Lear, ed. Conejero, 87.
${ }^{41}$ Parra, Lear, OC II, 420.
${ }^{42}$ Shakespeare, King Lear, II, iv, 85
${ }^{43}$ Shakespeare, Lear, ed. Conejero, 94
${ }^{44}$ Parra, Lear, OC II, 429.
${ }^{45}$ Ibídem, 434.
${ }^{46}$ Ibídem, 437.
${ }^{47}$ Ibídem, 441.
${ }^{48}$ Ibídem, 457.
${ }^{49}$ Ibídem, 677.
${ }^{50}$ En un momento de su traducción, por ejemplo, Neruda transforma el tema del horror de Julieta por la ausencia de Romeo en el tema de la injusticia del destierro. Así, el original de Shakespeare - “"Romeo is banished' / There is no end, no limit, measure, bound / In that word's death" (III, ii, 95) - se transforma en: "Romeo 'desterrado'. Esa palabra / no tiene término / la muerte que contiene esa palabra” (p. 69 en traducción de Neruda). Mientras que el parlamento de Julieta en el original hace hincapié en la condición de Romeo como desterrado, la traducción de Neruda hace hincapié en la condición de cualquier "desterrado". Citamos la traducción de Neruda en Cuadernos de Teatro n. ${ }^{\circ}$ 1, diciembre, 1979.. 
Shakespeare, pero Neruda no mezcla una multiplicidad de registros de expresión lingüística. Opta, más bien, por un lenguaje directo y coloquial en un registro único, aun cuando intenta reproducir algunos de los efectos poéticos de Shakespeare. En una escena de Romeo y Julieta con algunos paralelos con la de Edgar y Gloucester que citamos más arriba, un fraile encuentra una coartada para evitar el suicidio de Julieta, cuando le propone que tome una pomada con la que dará la impresión de haber muerto:

Hold, daughter! I do spy a kind of hope,

Which craves as desperate an execution

As that is desperate which we would prevent.

If [...] thou hast the strength of will to slay thyself,

Then it is likely thou wilt take

A thing like death to chide away this shame,

That copest with death himself to scape from it. ${ }^{51}$

La poesía del parlamento del fraile depende de la personificación de la esperanza, de la muerte y de la vergüenza; de dos usos distintos del concepto de "desesperación", y de la personificación de una misma palabra en dos sentidos distintos con el concepto de la muerte que se escapa de la muerta. Neruda no personifica a la esperanza como en el original de Shakespeare, pero reproduce el juego de los usos distintos del concepto de desesperación y de la personificación de la muerte en dos sentidos distintos en su traducción:

Calma, hija mía. ¡Existe una esperanza!

¡Para esta situación desesperada una desesperada solución!

Si en verdad te dispones a morir [...]

Tal vez será posible que te atrevas

A simular la muerte, de este modo

Desafiarás la muerte con la muerte. ${ }^{52}$

${ }^{51}$ Shakespeare, Romeo and Juliet (Nueva York: The Pelican Shakespeare), IV, i, 117.

52 Neruda, Cuadernos de Teatro, 80. 


\section{ARROJOS DE UN TÍTULO}

La libertad más notable y sugerente de la traducción de Nicanor Parra de El rey Lear de Shakespeare es su título: Lear. Rey y mendigo. Éste presupone un cambio fundamental en relación con el original de Shakespeare, y el asidero de la transformación de la obra de Shakespeare en una obra más cercana a las preocupaciones sociales de Parra. A la luz de la traducción, el título de Parra puede leerse de dos modos: como una progresión de monarca a mendigo, o como los dos sustantivos con los que se puede pensar en el mismo personaje. Este título encaja con la visión y con el tono de la traducción de Parra, pero la etiqueta de "mendigo" aplicada al rey Lear desentona con el mundo literario de Shakespeare, en el cual los monarcas y los nobles que han perdido su poder y sus posesiones mantienen sin embargo el sentimiento del derecho a su título, como cuando Ricardo II afirma su condición real aun cuando pierde su poder:

My crown I am; but still my griefs are mine:

You may my glories and my state depose,

But not my griefs; still am I king of those.

(Soy mi corona; y mis penas son aún mías:

Podrás destituirme de mis glorias y de mi estado,

Pero no de mis penas; todavía soy rey de ellas). ${ }^{53}$

El Lear de Shakespeare tampoco duda de su condición de rey, aun cuando ha perdido su gloria y su estado, aun cuando su morada es la intemperie y sucumbe a la locura. La humillación de la mendicidad es incompatible con el comportamiento de los monarcas caídos de Shakespeare. El rey Lear de Shakespeare ha cedido sus territorios y su poder, pero no ha cedido su título y hasta sus hijas ingratas lo tratan con las formas que corresponden a su condición real. El único personaje que rompe los protocolos es el que tiene derecho de hacerlo: su bufón, y lo hace para insistirle una y otra vez que ha sido un error ceder su reino y su poder. En el mundo literario de Shakespeare los monarcas pueden perder su poder, pero la monarquía hereditaria es el eje del orden hu-

${ }^{53}$ William Shakespeare, Richard II, editada por Kenneth Muir (Nueva York: Signet Classics, 1988) IV, i, 119. La traducción es mía. En Shakespeare el personaje de Edgar se rebaja a un estado aun inferior al de Lear cuando finge ser un mendigo. 
mano. Lear se siente siempre rey, y aun cuando empieza a tomar alguna responsabilidad por sus propias fallas, insiste en que el mundo ha sido más injusto con él que él con el mundo. En sus momentos de mayor locura e impotencia afirma su condición real. Por ejemplo, en uno de sus desvaríos expresa la dolorosa ironía de que dispone del poder de consentir las injusticias de las que él y sus fieles han sido víctimas:

None does offend, none, I say, non; I'll able'em.

Take that of me, my friend, who have the power

To seal th'accuser's lip. ${ }^{54}$

(Nadie es culpable, nadie, os digo, nadie; yo los absuelvo.

Hacedme caso, amigo mío, pues yo tengo el poder

de sellarle los labios al que acusa) $)^{55}$

Parra transforma el desvarío de Lear en el que afirma absurdamente su poder en un consejo pragmático para proteger a un amigo fiel de los abusos del poder:

Encuéntrale razón amigo

A quien tiene el poder

De cerrarle la boca al delator. ${ }^{56}$

El respeto a la monarquía y a las prerrogativas de un monarca son ideas ajenas al mundo literario de Parra y a su traducción de El rey Lear, en la cual el mundo de los nobles es un circo de intrigas (Parra transforma la metáfora shakesperiana del teatro del mundo en la del circo del mundo) $)^{57}$, de injusticias y arbitrariedades. Allí, el estado de mendicidad adquiere una dimensión de dignidad ajena al mundo de Shakespeare pero consistente con las preocupaciones sociales de Parra, que están más cercanas a la adaptación cinematográfica de Grigori Kózintsev, de 1970, que del original de Shakespeare, porque el cineasta

${ }^{54}$ Shakespeare, King Lear, IV, vi, 169.

${ }^{55}$ Shakespeare, Lear, ed. Conejero, 166.

${ }^{56}$ Parra, Lear, OC II, 508.

${ }^{57} \mathrm{Si}$ el Lear de Shakespeare dice que los seres humanos nacen en "este escenario de locos" ("to this great stage of fools", IV, vi, 181), el de Parra dice: "A este gran circo gran”, Lear, OC II, 509. 
soviético presenta, como lo ha explicado Roger Manvell, "una civilización que se está desmoronando por los males de la desigualdad y de la injusticia". ${ }^{58}$ En la película de Kózintsev, Lear pierde la petulancia de la majestad para convertirse en un miserable como los miserables con los que se encuentra, ya que él y ellos están vestidos de la misma manera. Es solamente después de perder su arrogancia y sufrir la miseria que logra una sabiduría a la que no estaba en condiciones de llegar antes de haber caído de las alturas del poder. Como lo ha explicado Mark Sokolyansky: "[el Lear de Kózintsev] no es el tirano arrogante, sino un hombre viejo que lo ha perdido todo en esta vida y por sus sufrimientos ha alcanzado un sentido superior de la justicia". ${ }^{59}$

En un espíritu consonante, el epígrafe que Parra elige para su Lear es una de cita de Goethe que modifica con la misma libertad y transparencia con la que modifica el título de Shakespeare (y con efectos equivalentes). La cita en alemán dice: "Ein alter Mann ist stets ein König Lear" (Un hombre viejo es siempre un Rey Lear). Pero Parra sustituye "hombre" por "pobre" para hacer hincapié en la precariedad económica de los desposeídos: "Un pobre viejo siempre es un Rey Lear". El original de Goethe proviene de uno de sus "Spruchdichtungen" (dichos en forma poética), en el cual el poeta alemán no hace ninguna referencia a los achaques económicos de la vejez, porque se trata de una meditación sobre las dificultades de los viejos para reconocer la pérdida de su juventud y el final de la vida activa. ${ }^{60}$ A Nicanor Parra no le interesa,

58 Roger Manvell, Shakespeare and the Film (New Jersey: Barnes \& Co., 1979), 84.

${ }^{59}$ Mark Sokolyansky, “Grigori Kózintsev's Hamlet and King Lear”, en The Cambridge Companion to Shakespeare on Film, editado por Russell Jackson (Cambridge: Cambridge University Press, 2000), 206.

60 "Ein alter Mann ist stets ein König Lear! -

Was Hand in Hand mitwirkte, stritt,

Ist längst vorbeigegangen;

Was mit und an dir liebte, litt,

Hat sich woanders angehangen.

Die Jugend ist um ihretwillen hier,

Es wäre törig, zu verlangen:

Komm, ältele du mit mir",

Johann Wolfgang von Goethe, Goethe's Werke in zehn Bänden, Zahme Xenien (Zürich und Stuttgart: Artemis Verlag, 1961), 605. 
como a Goethe, ingresar en el mundo de Shakespeare para darle una prioridad al tema del deterioro del ser humano que llega a una edad avanzada. Parra prefiere hacer hincapié en los abusos e injusticias del mundo de la corte, como una manera de responder a los problemas del momento que resuenan con los temas de la obra. En el poema-prólogo a su traducción, Parra lo dice con fuerza:

En un mundo desprovisto de racionalidad

La poesía no puede ser otra cosa

Que la mala consciencia de la época. ${ }^{61}$

En este mismo espíritu, en el ya citado "Paralelo con Hamlet" Parra hace una comparación entre la búsqueda de justicia de Hamlet y la de uno de los hijos naturales de Pedro Páramo de la novela de Juan Rulfo. En este "paralelo", la voz poética de Parra da a entender que la injusticia mayor no corresponde a las intrigas de la corte que Parra llama "delitos isabelinos", sino que a las ofensas económicas:

Pedro Páramo debe morir

Aunque no $\mathrm{x}$ delitos isabelinos

Ojo

$\mathrm{x}$ ofensas de orden económico... ${ }^{62}$

En el mundo literario de Parra, el mendigo como víctima de un orden económico adquiere una dignidad especial porque justifica la razón de ser de la poesía. En "Mendigo", un poema de Canciones rusas (1967), la voz poética de Parra hace un recorrido por los oficios del mundo moderno, expresando suspicacia por el nacionalismo de los militares y por la honestidad de los comerciantes, para concluir con los siguientes versos, en los que la humillación de la mendicidad y la actividad del poeta son dos caras de una misma moneda (palabra con la que, no en vano, cierra el poema):

\footnotetext{
${ }^{61}$ Parra, Lear, OC II, 346.

${ }^{62}$ Parra, "Paralelo con Hamlet", OC II, 577.
} 


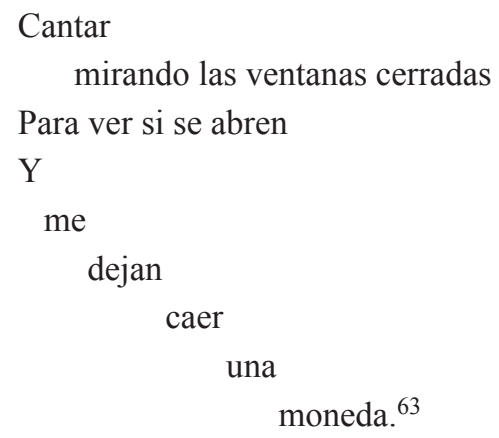

En "Los vicios del mundo moderno", ${ }^{64}$ Parra se refiere a los "delincuentes modernos" y a su "afán desmedido de poder y de lucro, / La carrera del oro, / La fatídica danza de los dólares" 65 que "están autorizados para concurrir diariamente a parques y jardines / Provistos de poderosos anteojos y de relojes de bolsillo". Son estos hombres poderosos los que controlan los medios de comunicación pero también a los desposeídos a quienes Parra se refiere como mendigos: "Controlan a fotógrafos y mendigos / que deambulan por los alrededores" 66 . El concepto del mendigo también aparece en "Recuerdos de juventud", en donde la voz poética de Parra ofrece unas reflexiones que podrían resumir algunos temas de su traducción de Lear:

Lo cierto es que yo iba de un lado a otro,

A veces chocaba con los árboles,

Chocaba con los mendigos [...]

De todo eso resultó un sentimiento de asco,

Resultó una tempestad de frases incoherentes,

Amenazas, insultos, juramentos que no venían al caso. ${ }^{67}$

Y como si se tratara de su propia respuesta a "Los vicios del mundo moderno", el Lear de Parra dice:

${ }^{63}$ Nicanor Parra, "Mendigo", de Canciones rusas, en OC I, 157.

${ }^{64}$ Nicanor Parra, "Los vicios del mundo moderno", de Poemas y antipoemas, en $O C I, 55$.

${ }^{65}$ Ibídem, 56.

${ }^{66}$ Ibídem, 55.

${ }^{67}$ Nicanor Parra, "Recuerdos de juventud", de Poemas y antipoemas, en $O C$ I, 44. El Lear de Parra dice: "La tempestad a mí no me dará tregua / Para pensar en cosas más dolorosas", Lear, OC II, 452. 
...que el magnate

Experimente en carne propia

Los sufrimientos del pobre infeliz

Para que vea con sus propios ojos,

Que lo superfluo debe ir a ellos: A los pobres!

El cielo así parecerá más justo ${ }^{68}$

Pero este Lear no es el Lear de Shakespeare, sino el de Parra. En el original de Shakespeare, Lear reconoce que él no ha sido justo con los miserables, pero no duda de las prerrogativas de los nobles:

Pomp;

Expose thyself to feel what wretches feel, that thou mayst shake the superflux to them, And show the Heavens more just.

En el original, Shakespeare establece un contraste entre el concepto de "pomp", que se refiere a las ceremonias de una corte, y la palabra "wretch", que se refiere a los miserables, para así hacer hincapié en la responsabilidad de los nobles para tratar a sus sujetos con justicia. En su traducción, en cambio, Parra hace hincapié en las injusticias de un mundo social. El poeta chileno borra la connotación real de "pomp" del original para hablar de la experiencia de un "magnate", y en vez de "miserable" dice "pobre infeliz". Como con su modificación del epígrafe de Goethe, Parra añade "A los pobres!", una locución que no está en Shakespeare para insistir en la injusticia de una condición económica. León Tolstoi, a quien Parra menciona en el poema-prólogo de su versión de El rey Lear como uno de los detractores de Shakespeare, le reprochó al poeta inglés su sometimiento a los valores injustos de la nobleza. Ésta no es una crítica posible a Lear. Rey y mendigo, que rescata a Shakespeare de ese tipo de crítica para que pueda ser leído con otros ojos, y éste es solamente uno de los méritos de este impresionante trabajo literario.

En una entrevista con Juan Antonio de Muñoz sobre su Lear. Rey $y$ mendigo, Parra afirma que nunca trabajó tan intensamente en su vida 
de escritor y lo considera "el proyecto de mi vida. Todas las demás líneas convergen alli" ${ }^{69}$. En este imponente trabajo literario, Parra se ha nutrido de muchas fuentes para crear una obra porosa, con vestigios y rastros de otras obras. Su trabajo con Lear, pero también con el soneto XVIII y con Hamlet, está prefigurado en sus obras anteriores, a las que sus ejercicios shakesperianos le otorgan una nueva riqueza retrospectiva. Es por ello que la lectura de sus obras literarias inspiradas en Shakespeare se enriquece a la luz de su propia poesía, pero su poesía también se ha enriquecido gracias a ellas. EP

${ }^{69}$ Citado en las notas de las OC II, 1071. 